\title{
Oxidative dehydrogenation of ethylbenzene to styrene over ultra-dispersed diamond and onion-like carbon
}

\author{
Dangsheng Su ${ }^{a, d}, *$, Nadezhda I. Maksimova ${ }^{a}$, Gerhard Mestl ${ }^{a}$, Vladimir L.Kuznetsov ${ }^{b}$, \\ Valérie Keller ${ }^{\mathrm{c}, \mathrm{d}}$, Robert Schlögl ${ }^{\mathrm{a}, \mathrm{d}}$ and Nicolas Keller ${ }^{\mathrm{c}, \mathrm{d}}$,* \\ ${ }^{a}$ Fritz-Haber-Institut der Max-Planck-Gesellschaft, Faradayweg 4-6, 14195 Berlin, Germany \\ ${ }^{\mathrm{b}}$ Boreskov Institute of Catalysis, Lavrentieva 5, Novosibirsk 630090, Russia \\ ${ }^{c}$ Laboratoire des Matériaux, Surfaces et Procédés pour la Catalyse, CNRS, Louis Pasteur \\ University, 25 rue Becquerel, 67087 Strasbourg Cedex, France \\ ${ }^{\mathrm{d}}$ European Laboratory for Catalysis and Surface Sciences (ELCASS) \\ *Corresponding authors. Tel.: +49 30841354 06; fax: +49 3084134405 (D. Su), tel.: +33 3902428 11; fax: +33 \\ 390242761 (N. Keller).
}

\begin{abstract}
The catalytic properties of $\mathrm{sp}^{3}$-hybridized ultra-dispersed diamond and $\mathrm{sp}^{2}$-hybridized onion-like carbon in the oxidative dehydrogenation of ethylbenzene to styrene were investigated, highlighting the structure sensitivity of the reaction. The $\mathrm{sp}^{3}$-carbon led initially to $\mathrm{C}-\mathrm{C}$ cleavage and benzene formation, while a switchover of the main reaction pathway into the styrene formation occurred with time on stream due to the formation of surface $\mathrm{sp}^{2}$ carbon, required for the selective styrene formation. This was confirmed by the behavior and the high stable styrene selectivity shown by onion-like carbons. High temperature oxygen pre-treatment created catalytically active species at the $\mathrm{sp}^{2}$ carbon surface, confirming that a high thermal stability carbon-oxygen complex was the active surface site for forming styrene.
\end{abstract}

\section{Introduction}

The styrene monomer involved in polymer syntheses is nowadays industrially produced by direct ethylbenzene dehydrogenation, a strongly endothermic process carried out at high temperatures (873-953 K) over potassium promoted iron oxide catalysts in the presence of a large excess of overheated steam [1]. This process suffers from drawbacks : (i) thermodynamic limitation, (ii) large amount of wasted energy, (iii) irreversible catalyst deactivation and (iv) coke deposition [2]. Since this synthesis is one of the ten largest industrial processes, there is a strong incentive to develop alternative technologies such as dehydrogenation followed by hydrogen oxidation [3], dry dehydrogenation with $\mathrm{CO}_{2}$ [4], membrane technologies [5], or the oxidative dehydrogenation $(\mathrm{ODH})$, which is one of the most elegant and promising reaction due to its exothermicity, the absence of detrimental thermodynamic limitations and lower operation temperatures [6].

The performances of mainly oxidic catalysts for the $\mathrm{ODH}$ of ethylbenzene to styrene were featured by an induction period during which an increase in the activity was related to carbon deposition or coke formation, suggesting a direct dehydrogenating activity of carbon itself [7]. Amongst other carbonaceous catalysts [8] and [9], focuse was made on activated carbon due to its industrial interest and its high surface area [10], [11], [12] and [13]. The influence of its textural structure and its surface chemistry was especially investigated. However, activated carbon did not exhibit high and stable styrene yield. Indeed, its instability towards oxygen under oxidative conditions required working at low reaction temperature in order to avoid the catalyst combustion, and thus led to low styrene yields. By contrast, high stable yields compared to technical catalysts and activated carbons were obtained on graphite [14] and [15], and non-planar $\mathrm{sp}^{2}$-carbon nanostructures like carbon nanofilaments or nanotubes [15] and [16] and onion-like 
carbon (OLC) [17] and [18]. The very low porosity of such $\mathrm{sp}^{2}$-carbon nanostructures was beneficial, since the porosity of catalysts such as activated carbons seemed to play a negative role by hindering the styrene desorption, which limits the ethylbenzene conversion and leads to nonselective consecutive reactions [13], [17], [19] and [20].

Pre-oxidizing the activated carbons for creating oxygenated surface active sites revealed a correlation between the ODH activity and the concentration of carbonyl/quinone groups, assigned as the active sites for the ODH reaction [13]. Quasi in situ XPS coupled with mass spectrometry was carried out during ODH on activated carbon fibers, confirming the involvment of carbonyl/quinone and hydroxyl groups in the ODH of ethylbenzene [21].

Till now, only $\mathrm{sp}^{2}$ carbons have been studied for ODH. This article reports the effect of the unique structural variety of carbon, i.e. the carbon allotropies with $\mathrm{sp}^{2}$ - and $\mathrm{sp}^{3}$-local electronic configurations, on the catalytic behavior. Ultra-dispersed diamond (UDD) and onion-like carbon (OLC) were selected as representative $\mathrm{sp}^{3}$ and $\mathrm{sp}^{2}$ carbon structures, with similar size and shape to minimize size and morphology effects. They were model carbons due to a very low internal porosity and well-defined surfaces, allowing the study to be performed as a function of the surface functionalization by pre-treating the catalysts.

\section{Experimental}

\subsection{Materials}

The $\mathrm{sp}^{3}$-hybridized UDD were obtained by an explosion method, and isolated from the detonation soot by oxidative treatment with $\mathrm{H}_{2} \mathrm{SO}_{4}$ and $\mathrm{HClO}_{4}$ acids [22]. The sample consisted of $95 \%$ of $\mathrm{sp}^{3}$-carbon with a $5 \mathrm{~nm}$ mean particle size. $\mathrm{Sp}^{2}$-hybridized OLC with concentric graphene shell structure were produced by annealing of UDD at $2140 \mathrm{~K}$ and under $10^{-6}$ Torr, leading to more than $95 \% \mathrm{sp}^{2}$-carbon, with similar shapes and sizes [23].

\subsection{Catalytic tests}

The reaction was carried out at $788 \mathrm{~K}$ in a quartz tube reactor ( $4 \mathrm{~mm}$ i.d.) using $0.04 \mathrm{~g}$ of catalyst, which corresponded to a $2 \mathrm{~mm}$ length catalytic bed. Helium and oxygen were fed into the reactor by mass flow controllers, and ethylbenzene in flowing He was provided by a saturator kept at $308 \mathrm{~K}$ (ethylbenzene vapour pressure of $2.16 \mathrm{kPa}$ ). Oxygen was added to the flow in a molar ratio of $1: 1$ to ethylbenzene and the total flow was kept at $10 \mathrm{ml} / \mathrm{min}$ (Liquid hourly space velocity of $0.5 \mathrm{~h}^{-1}$ ). The products were analyzed on-line by a gas chromatograph equipped with a 5\% SP-1200/1.75\% Bentone 34 packed column for the hydrocarbons and a carboxen 1010 PLOT column for the permanent gases, coupled to FID and TCD detectors, respectively. The catalyst was evaluated as usual by means of the ethylbenzene conversion, defined as the fraction of the inlet ethylbenzene to be converted, the styrene selectivity defined as the fraction of the converted ethylbenzene to be transformed into styrene, and the styrene yield, which corresponds to the fraction of the inlet ethylbenzene to be dehydrogenated into styrene and is therefore calculated as the product of conversion by selectivity.

Pretreatment experiments consisted of heating the samples (i) in pure He at $843 \mathrm{~K}$ for $3 \mathrm{~h}$; (ii) in a $\mathrm{H}_{2}(10 \%) / \mathrm{He}$ feed at $843 \mathrm{~K}$ for $3 \mathrm{~h}$ and (iii) in a $\mathrm{O}_{2}(2 \%) / \mathrm{He}$ feed at $788 \mathrm{~K}$ and $843 \mathrm{~K}$ for $3 \mathrm{~h}$, before switching to the reaction feed and performing the tests at $788 \mathrm{~K}$. The reactor was cooled down to room temperature in flowing He to avoid hydrocarbon adsorption on the catalyst. The transfer of the catalysts to air however leads to water adsorption. Since strongly basic surface functions cannot be generated by exposing carbon to air at room temperature, adsorbed species (desorbing at low temperatures) and intrinsic, basic functionalities (decomposing at high temperatures) can be distinguished. 


\subsection{Characterization}

Transmission electron microscopy (TEM) was performed using a Philips CM200-FEG microscope operating at $200 \mathrm{kV}$ acceleration voltage. Raman-spectroscopy was conducted with a LabRam spectrometer (Dilor) using a $632 \mathrm{~nm}$ excitation at $25 \mathrm{~mW}$ laser power with a $2.5 \mathrm{~cm}^{-1}$ resolution. Infrared (IR) spectroscopy was performed on a Fourier transform spectrometer (BOMEM MB-102). The samples were prepared as suspensions by pressing in $\mathrm{KBr}$. The BET and microporous surface area analysis were performed using $\mathrm{N}_{2}$ at $77 \mathrm{~K}$ on materials outgassed at $573 \mathrm{~K}$ for $3 \mathrm{~h}$, and were derived from the well-known BET and $t$-plot equation models, respectively. The $t$-plot consists of the analysis of the $v_{1}-t$ plot curve where $v_{1}$ is the volume of $\mathrm{N}_{2}$ adsorbed as liquid at a given pressure $P / P_{0}$ by the BET surface and $t$ is the statistical thickness obtained by dividing the volume of $\mathrm{N}_{2}$ adsorbed as liquid at a given pressure $P / P_{0}$ by the BET surface.

\section{Results}

\subsection{Catalytic study}

Fig. 1 shows the time on stream behavior of the UDD carbon catalysts for the ODH of ethylbenzene to styrene at $788 \mathrm{~K}$, compared with that of OLC. Briefly, the OLC catalyst exhibited an activation period of about $2 \mathrm{~h}$, from a minor initial activity to a conversion level of $92 \%$ at the steady-state, with an almost stable styrene selectivity at $68 \%$ allowing a high stable yield of $62 \%$ to be obtained (Fig. 1a). By contrast, an initial conversion of ethylbenzene of $93.5 \%$ with a selectivity to styrene of $26 \%$ and a styrene yield of $25 \%$ were observed on UDD carbons (Fig. 1b). The main by-products were benzene and $\mathrm{CO}_{2}$, with initial yields being 32.9\% and $30 \%$, respectively. Both benzene and $\mathrm{CO}_{2}$ yields decreased during the induction period before stabilizing at $8 \%$ and $23 \%$, respectively, whereas the styrene selectivity and the styrene yield both increased to $45 \%$ and $40 \%$, respectively (Fig. 1a). In parallel to the increase in styrene selectivity, the ethylbenzene conversion decreased slowly with time on stream before stabilizing at $85 \%$. The yields of other minor by-products such as $\mathrm{CO}$ or toluene remained unchanged during the catalytic test, at $4 \%$ and $1.9 \%$, respectively.

Fig. 1c shows the benzene to styrene ratio for UDD and OLC samples. The initial benzene to styrene ratio on the fresh $\mathrm{sp}^{3}$-carbon was 1.4 , much higher than that on $\mathrm{sp}^{2}$-carbon. Such a high benzene formation was not observed on OLC or other $\mathrm{sp}^{2}$-carbons [15], [16], [17] and [18], evidencing the $\mathrm{sp}^{3} / \mathrm{sp}^{2}$-carbon structure sensitivity of the $\mathrm{ODH}$ reaction under the given conditions. Together with the increase in styrene yield, the benzene to styrene ratio decreased to 0.3 during the induction period, showing a consecutive switch of the reaction pathway from benzene to styrene formation. However, the ratio at steady-state was still higher than that shown by $\mathrm{sp}^{2}$-carbon (Fig. 1c). The initial styrene yields were $25 \%$ and $40 \%$ on UDD and OLC, the styrene yield at steady-state reached $38 \%$ and $62 \%$, respectively (Table 1 ).

Table 1

Specific catalytic activities and surface areas of UDD and OLC materials

\begin{tabular}{|l|l|l|l|l|l|l|l|l|l|}
\hline Sample & \multicolumn{2}{|c|}{ Styrene yield (\%) } & \multicolumn{2}{|c|}{$\begin{array}{l}\text { Reaction rate, } \operatorname{lmol}_{\mathrm{EB}} /(\mathrm{g} \mathrm{s}) \\
{\left[\mathrm{mol}_{\mathrm{EB}} /\left(\mathrm{m}^{2} \mathrm{~s}\right)\right]}\end{array}$} & \multicolumn{2}{|c|}{$\begin{array}{l}\text { Specific surface } \\
\text { area, } \mathrm{m}^{2} / \mathrm{g}\end{array}$} & \multicolumn{2}{l|}{ Micropore area, $\mathrm{m}^{2} / \mathrm{g}$} \\
& Initial & $\begin{array}{l}\text { At } 10 \mathrm{~h} \text { on } \\
\text { stream }\end{array}$ & Initial & $\begin{array}{l}\text { At } 10 \mathrm{~h} \text { on } \\
\text { stream }\end{array}$ & Initial & $\begin{array}{l}\text { After } \\
\text { reaction }\end{array}$ & Initial & $\begin{array}{l}\text { After } \\
\text { reaction }\end{array}$ \\
\hline UDD & 25 & 38 & $37.6[0.13]$ & $34.1[0.17]$ & 297 & 199 & 25 & 0 \\
\hline OLC & 40 & 62 & $8.0[0.018]$ & $37.0[0.13]$ & 456 & $276:$ & 33 & 0 \\
\hline
\end{tabular}



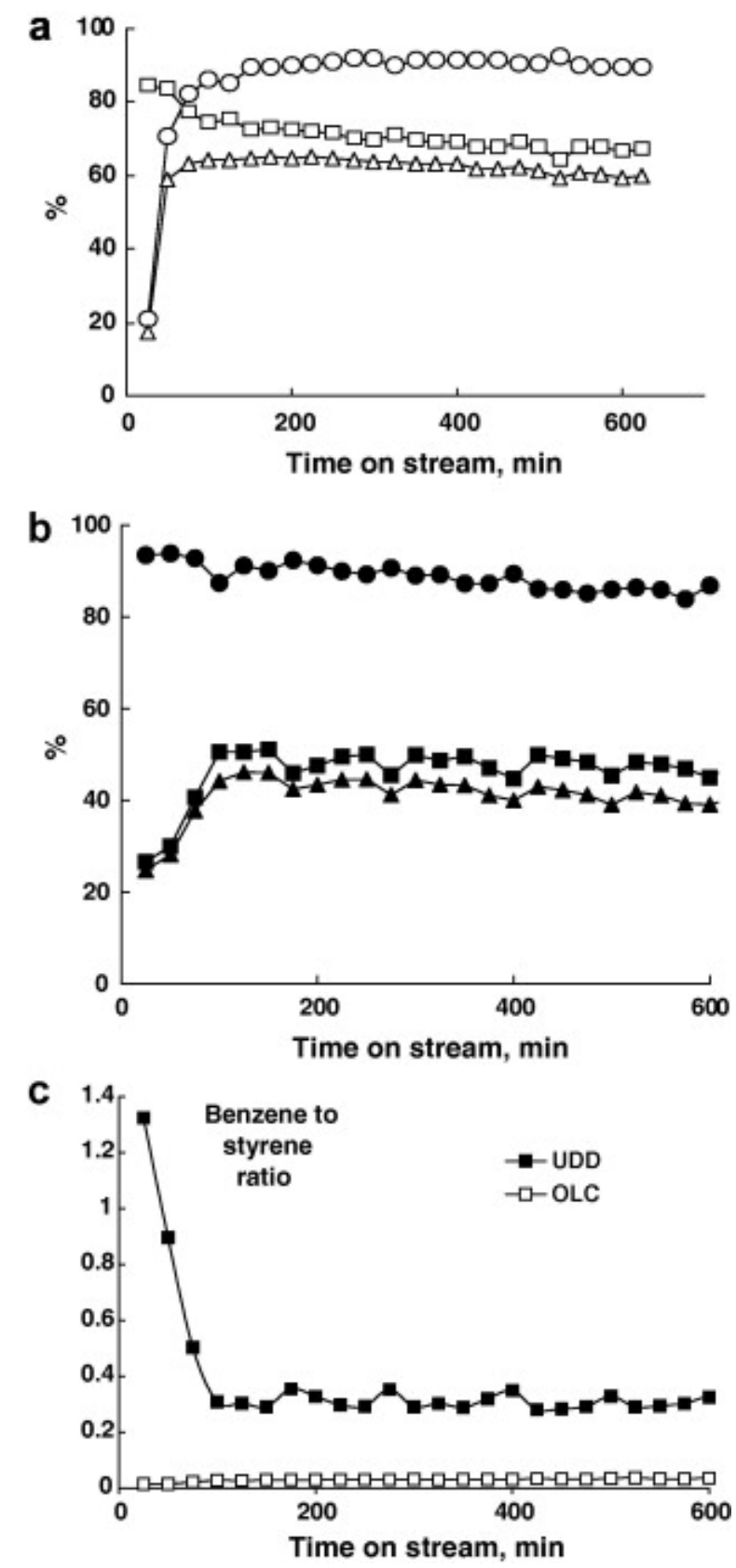

Fig. 1. Time on stream experiment of the ODH of ethylbenzene to styrene over the (a) OLC and (b) UDD catalysts at $788 \mathrm{~K}$. (c) Benzene to styrene molar ratio as a function of time on stream obtained over UDD and OLC catalysts.

The reaction rate confirmed the different behaviors of UDD and OLC (Table 1). They were expressed as $\mu \mathrm{mol}_{\mathrm{EB}} /(\mathrm{gs})$ and $\mu \mathrm{mol}_{\mathrm{EB}} /\left(\mathrm{m}^{2} \mathrm{~s}\right)$ in order to take into account the decrease in surface area of the nanostructured carbons during the test. The reaction rate in $\mu \mathrm{mol}_{\mathrm{EB}} /(\mathrm{g} \mathrm{s})$ on UDD slightly decreased on stream due to the decrease in conversion, while, considering the decrease in surface area of UDD from 297 to $199 \mathrm{~m}^{2} \mathrm{~g}^{-1}$, the reaction rate in $\mu \mathrm{mol}_{\mathrm{EB}} /\left(\mathrm{m}^{2} \mathrm{~s}\right)$ slightly increased during the $\mathrm{ODH}$ from 0.13 to $0.17 \mu \mathrm{mol}_{\mathrm{EB}} /\left(\mathrm{m}^{2} \mathrm{~s}\right)$. Contrarily, the initial reaction rate on OLC was $0.018 \mu \mathrm{mol}_{\mathrm{EB}} /\left(\mathrm{m}^{2} \mathrm{~s}\right)$ before strongly increasing to $0.13 \mu \mathrm{mol}_{\mathrm{EB}} /\left(\mathrm{m}^{2} \mathrm{~s}\right)$ during the induction period.

The catalytic behavior of both materials was also studied as a function of the surface functionalization, by pretreating UDD and $\mathrm{OLC}$ in $\mathrm{He}, \mathrm{H}_{2}$ and $\mathrm{O}_{2}$ (Fig. 2 and Fig. 3). After 
pretreatments in $\mathrm{He}$ and $\mathrm{H}_{2}$, the initial ethylbenzene conversions over UDD were $88 \%$ and $91 \%$, respectively, and $73 \%$ over the UDD pretreated at $843 \mathrm{~K}$ in $\mathrm{O}_{2}$ (Fig. 2a). On stream, the conversion decreased to $70-72 \%$ on UDD pretreated in $\mathrm{He}$ and $\mathrm{H}_{2}$, and to $45 \%$ on the $\mathrm{O}_{2-}$ pretreated catalyst, the conversion on UDD pretreated in $\mathrm{O}_{2}$ remaining lower than the conversion obtained on catalysts pretreated in $\mathrm{H}_{2}$ and $\mathrm{He}$. The influence of the pretreatment on the ethylbenzene conversion could be explained by a modification in the anchoring sites at the UDD surface, which decreased the density of the $\mathrm{sp}^{2}$ carbon deposit located at the UDD surface at the beginning of the test. The pretreatment of OLC resulted in a different catalytic behavior (Fig. $2 b$ ). The induction period observed on the non-treated OLC sample was still observed after He and $\mathrm{H}_{2}$ pretreatment, with a steady-state conversion around $85 \%$. By contrast, no induction period was observed after the pre-treatment at $843 \mathrm{~K}$ in $\mathrm{O}_{2}$, with a stable conversion at $80-85 \%$. The selectivity pattern obtained with UDD and OLC was not affected by the pretreatments at 788 $\mathrm{K}$ (not shown). This could be explained by the similar nature of the $\mathrm{sp}^{2}$ carbon deposit formed during the test at the catalyst surface whatever the pretreatment nature.
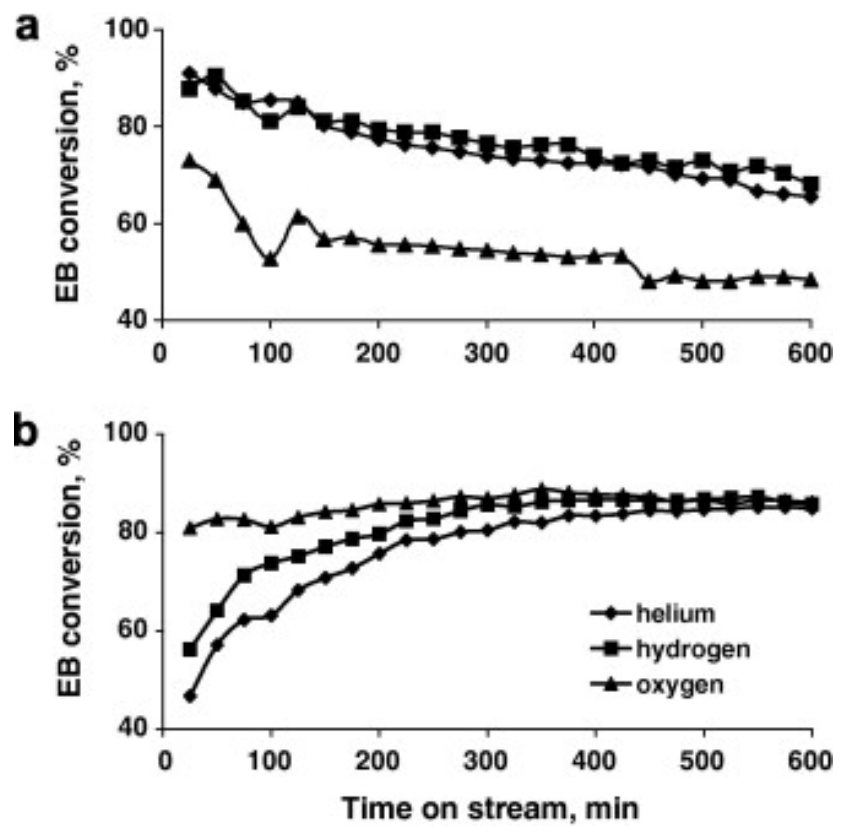

Fig. 2. Ethylbenzene conversions obtained at $788 \mathrm{~K}$ over UDD (a) and OLC (b) catalysts after pre-treatments in helium, hydrogen and oxygen at $843 \mathrm{~K}$.

The influence of the $\mathrm{O}_{2}$ pretreatment temperature was crucial to study on OLC (Fig. 3), since an on stream induction period with conversion increase was observed at a reaction temperature of $788 \mathrm{~K}$, while pretreating OLC at $788 \mathrm{~K}$ did not remove the induction period, both conversion and yield increasing during the first hours of test after pretreatment. It was worth noting that the pretreatment at $843 \mathrm{~K}$ suppressed the on stream activation period with stable conversion and styrene yield of $80 \%$ and $68 \%$, respectively. 

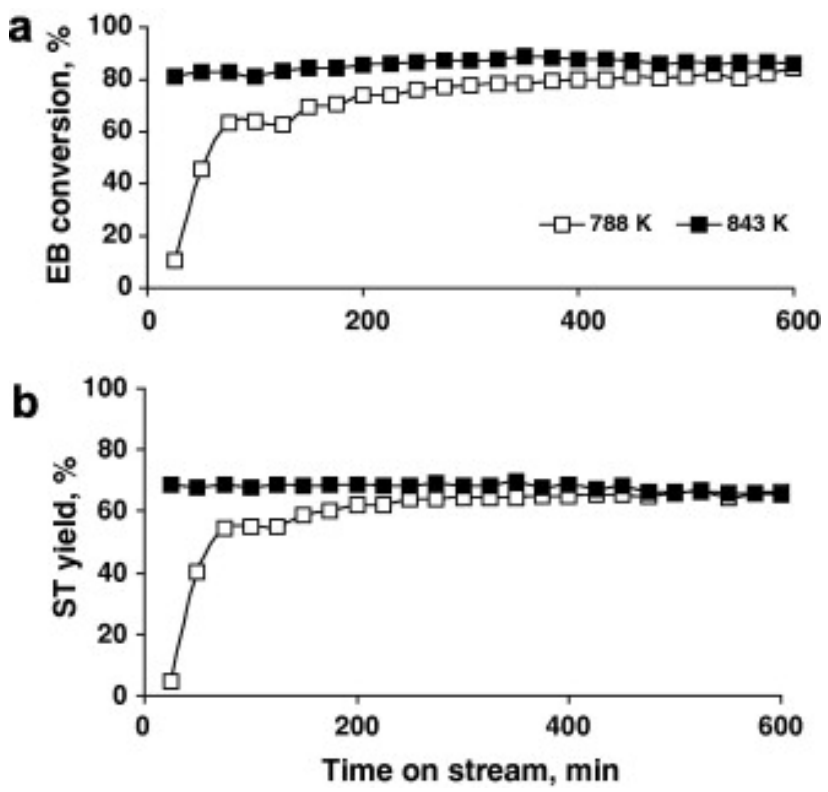

Fig. 3. Ethylbenzene conversions (a) and styrene yields (b) obtained with time on stream over the OLC catalyst pretreated at $788 \mathrm{~K}$ and $843 \mathrm{~K}$ in oxygen.

\subsection{Characterization}

UDD and OLC materials displayed specific surface areas close to the geometric surfaces, with residual micropore contents resulting from the aggregation and the sintering of the nanostructured carbons during the synthesis process, representing $7-8 \%$ of the specific surface areas, as usually reported [17] and [18]. BET measurements showed that the surface area decreased with almost the same ratio for both UDD and OLC samples, and the very low microporosity disappeared during the ODH test (Table 1). Such slight textural changes suggest the filling of the scarce micropores located in the samples with soft coke deposited during the reaction. A direct correlation was not observed between the catalytic activities and specific surface areas (Table 1).

The [111] lattice fringes of diamond observed on the high-resolution TEM image of the fresh UDD were clearly resolved (Fig. 4a). By contrast, the used UDD surface was covered by graphitized overlayers after $24 \mathrm{~h}$ of time on stream, which can correspond to deposited carbon during the reaction due to the polymerization of reactants or products. (Fig. 4b). It should be mentioned that uncovered UDDs were still present explaining the residual formation of benzene even after a long running time (Fig. 1c).

Both fresh and used UDD catalysts were further characterized by using Raman-spectroscopy in the 1000-1750 $\mathrm{cm}^{-1}$ range (Fig. 5, Table 2). The Raman spectrum of the fresh UDD exhibits bands at $1324 \mathrm{~cm}^{-1}$ and $1224 \mathrm{~cm}^{-1}$, characteristic for $\mathrm{sp}^{3}$-carbon in diamond structure [24]. The weak broad features at $1590 \mathrm{~cm}^{-1}$ was assigned to the carbon impurity in the UDD catalysts, as mentioned in the experimental part. By contrast, the used UDD sample showed a strong intensity band at $1594 \mathrm{~cm}^{-1}$ ( $\mathrm{G}$ and $\mathrm{D}^{\prime}$ bands), revealing a pronounced presence of $\mathrm{sp}^{2}$-carbon, the very broad band around $1330 \mathrm{~cm}^{-1}$ corresponding to disordered $\mathrm{sp}^{2}$-(D band) and $\mathrm{sp}^{3}$-carbon. These results substantiate the formation of $\mathrm{sp}^{2}$-carbon on the UDD surface during the catalytic test, as revealed by TEM. 

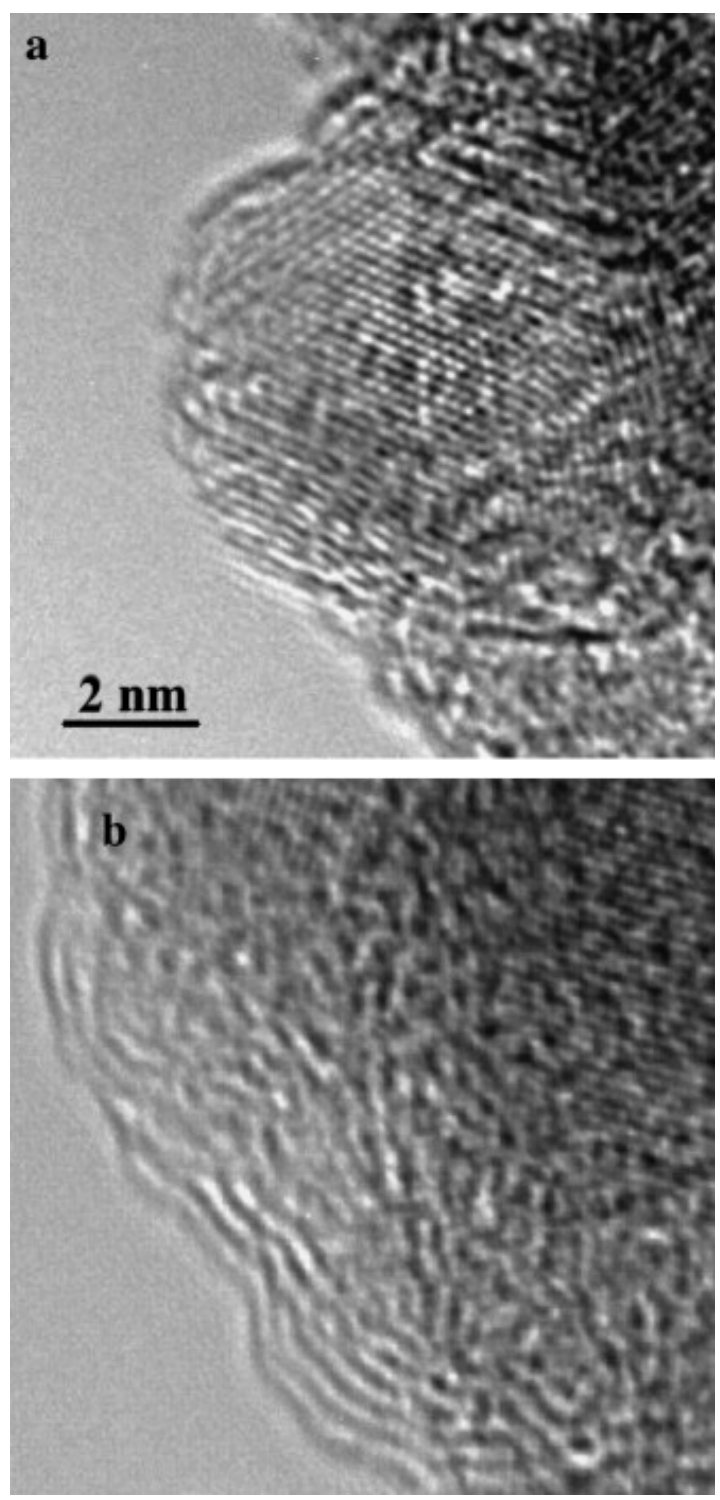

Fig. 4. TEM image of UDD (a) before and (b) after reaction at $788 \mathrm{~K}$ for $600 \mathrm{~min}$.

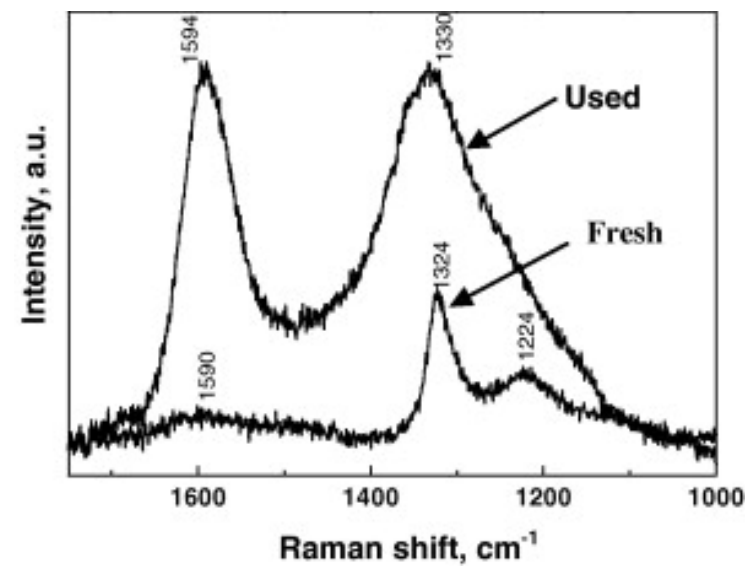

Fig. 5. Raman spectra of UDD before and after reaction at $788 \mathrm{~K}$ for $600 \mathrm{~min}$. 
Table 2

Raman assignments of carbon structures, adapted from [24]

Carbon structure

Raman band

Ordered (G) and disordered (D0) graphite

Around $1594 \mathrm{~cm}^{-1}$

Disordered graphite (D)

Diamond

$1330 \mathrm{~cm}_{-} 1$

Diamond

$1324 \mathrm{~cm}^{-1}$

$1224 \mathrm{~cm}^{-1}$

IR spectroscopy was performed to evidence the change during the reaction in the functional groups located at the UDD surface (Fig. 6, Table 3) [25]. The fresh UDD showed a band at 1626 $\mathrm{cm}^{-1}$ assigned to the vibration of adsorbed water [26], also observed on the used UDD, although overlapped by the signal due to the $\mathrm{C}=\mathrm{C}$ bonds of the deposited graphitic carbon. The stretching frequency at $1400 \mathrm{~cm}^{-1}$ assigned to the bending vibrations of $\mathrm{OH}$ groups was accordingly present on both fresh and used UDD surface. The fresh material showed a strong absorbance at $1787 \mathrm{~cm}^{-1}$ and a band at $1262 \mathrm{~cm}^{-1}$, assigned to the carboxylic acid groups [27] and [28], both being not observed after reaction. This was attributed to the thermal instability of the carboxylic acid surface groups, known to decompose for temperatures higher than $540 \mathrm{~K}$. The absorption maximum at $1106 \mathrm{~cm}^{-1}$ and the shoulder at $1053 \mathrm{~cm}^{-1}$ observed on the fresh UDD, was located in the spectral region corresponding to $\mathrm{C}-\mathrm{O}$ stretching vibrations of ether-type groups and alcohols [25] and [29]. After reaction, these features disappeared or at least reduced in intensity. The used catalyst exhibited an intense peak at $1013 \mathrm{~cm}^{-1}$ due to the increased $\mathrm{C}-\mathrm{OH}$ groups on its surface (a small amount of the $\mathrm{C}-\mathrm{O}$ stretching contribution cannot be excluded due to the possible overlapping of the vibration peaks). The shoulder at $1550 \mathrm{~cm}^{-1}$ corresponded to the vibration of quinone groups on the used catalyst, which was not observed on the fresh UDD. Hence, the IR analysis confirmed changes of the surface functionalities of $\mathrm{sp}^{3}$-carbon during the reaction, i.e. the disappearance of carboxylic acid groups and the appearance of basic $\mathrm{C}=\mathrm{O}, \mathrm{C}-$ $\mathrm{OH}$ and ether groups.

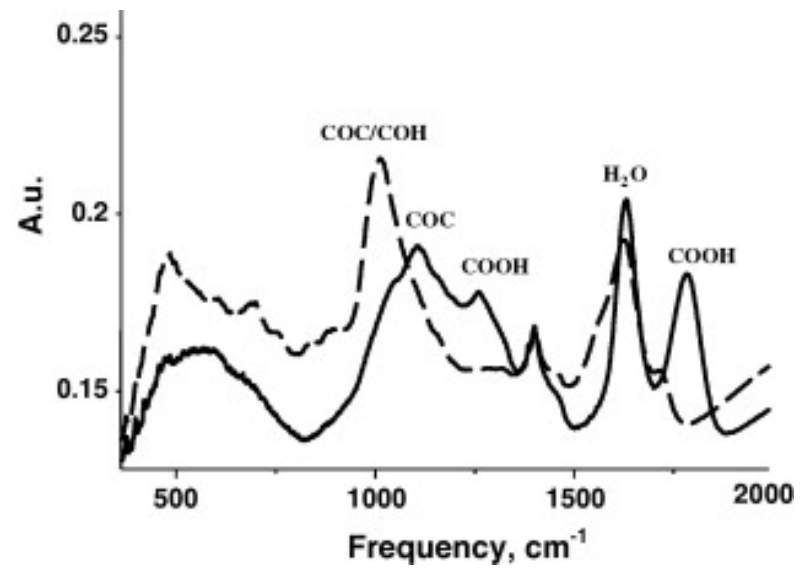

Fig. 6 IR spectra of UDD before (solid line) and after reaction (dashed line) at $788 \mathrm{~K}$ for $600 \mathrm{~min}$. 
Table 3

IR assignments of functional groups on carbon surfaces, adapted from [25]

\begin{tabular}{lll} 
& Group or functionality & Assignment regions (cm \\
\hline & $1000-1500$ & $1500-2050$ \\
C-O in ethers (stretching) & $1000-1300$ & \\
Alcohols & $1049-1276$ & \\
& & \\
Phenolic groups: & & \\
C-OH (stretching) & $1000-1220$ & $1100-15001590-1600$ \\
O-H & $1160-1200$ & \\
Carbonates & carboxyl-carbonates & \\
C=C aromatic (stretching) & $1585-1600$ & $1665-1760$ \\
Quinones & $1550-1680$ & $1675-1790$ \\
Carboxylic acids & $1120-1200$ & $1740-1880$ \\
Lactones & $1160-1370$ & \\
Carboxylic anhydrides & $980-1300$ &
\end{tabular}

\subsection{Discussion}

The catalytic testing over UDD and OLC highlighted totally different behaviors of $\mathrm{sp}^{2}$ and $\mathrm{sp}^{3}$ carbons for the styrene production, with an initial predominant benzene formation on the $\mathrm{sp}^{3}$ carbon, evidencing that $\mathrm{sp}^{3}$-carbon was not suited for the formation of the stable oxygenated species necessary for the dehydrogenation of ethylbenzene.

The differences in the initial behavior of the oxidized OLC materials clearly showed the creation of active sites at the OLC surface during the oxidative pre-treatment at $843 \mathrm{~K}$, whereas they were not formed when the oxidative pre-treatment was performed at the reaction temperature, i.e. 788 $\mathrm{K}$. The shift in temperature was attributed to the exothermicity of the ODH reaction. The active sites are high temperature $\mathrm{C}-\mathrm{O}$ functionalities on the carbon surface. Creation of active sites on activated carbon was already reported even at much lower temperatures by oxygen treatment [10], [11], [12] and [13], a reactive coke, more active than the catalysts, being observed after the induction period [14] while coke formation might not occur on OLC pretreated at higher temperature [17].

The decrease in the benzene formation and the increase in the styrene formation with time on stream on UDD corresponded to a switch of the reaction pathway from the predominant benzene to styrene formation, and could be correlated with the deposition of $\mathrm{sp}^{2}$-carbon overlayers during the induction period, as evidenced by TEM and Raman. One could propose that the $\mathrm{sp}^{3}$ nanostructured carbon catalyst switched on stream from a $\mathrm{sp}^{3}$ to a $\mathrm{sp}^{2}$ reactivity, residual benzene formation (Fig. 1c) resulting from uncovered $\mathrm{sp}^{3}$ centers reacting according to the initial $\mathrm{sp}^{3}$ based pathway.

The reactivity toward oxidation was depending on the diamond facets [30]. The oxidation rate on low index facets varied linearly with the oxygen pressure between 0.5 and 0.6 Torr in the 970 $1270 \mathrm{~K}$ range, the (111) facet with the highest rate, followed by the (110) and (100) facets. A graphitic deposit was detected on the (111) and (110) facets, while the (100) facet was free of graphitic layers at $920-1120 \mathrm{~K}$ with an activation energy for combustion of $230 \pm 10 \mathrm{~kJ} \mathrm{~mol}^{-1}$ in this temperature range [30]. By contrast, at 870-970 K, the (111) facet was also clean from any forms of carbon deposits with a similar measured activation energy of combustion for this plane at $230 \pm 10 \mathrm{~kJ} \mathrm{~mol}^{-1}$. Hence, it can be assumed that the UDD surfaces free of graphitic deposits 
might consist of (100) facets, while (111) facets might be covered by more reactive graphitic deposits according to [29]. This explained the remaining significant benzene yield of $8 \%$ on UDD at steady-state, due to the incomplete coverage of the UDD nanoparticles with $\mathrm{sp}^{2}$-carbon. This selective coverage of UDD surface planes by $\mathrm{sp}^{2}$ carbons confirmed that the $\mathrm{sp}^{2} / \mathrm{sp}^{3}$ carbon material comparison could not be reduced to a comparison between two $\mathrm{sp}^{2}$ carbons. In addition, the reactivity of the $\mathrm{sp}^{3}$ UDD and $\mathrm{sp}^{2}$ OLC was also influenced by the heat release for an exothermic reaction such as $\mathrm{ODH}$, and therefore the structural nature of the $\mathrm{sp}^{3}$ or $^{2} \mathrm{sp}^{2}$ core of the nanoparticles remained very important.

The reactivity of bridged diamond carbonyl groups differed from that of quinoidic carbonyl groups of graphitic carbon. The reactivity of diamond $\mathrm{C}=\mathrm{O}$ groups toward hydrogen is lower than that of basic, quinoidic carbonyl $\mathrm{C}=\mathrm{O}$ groups on $\mathrm{sp}^{2}$ carbon due to the ability of the aromatic system of graphene sheets to delocalize the carbon $\mathrm{p}_{z}$ electron after the attachment of a hydrogen atom and the formation of a hydroxyl group. In case of the reaction of $\mathrm{C}=\mathrm{O}$ groups on the diamond surface with incorporation of hydrogen, dangling bonds have to be formed at the carbon atom level. It can be proposed that the reactivity of $\mathrm{C}=\mathrm{O}$ groups on diamond varies with the diamond crystallographic planes, the most stable $\mathrm{C}=\mathrm{O}$ groups being localized on the (100) faces. The $\mathrm{C}=\mathrm{O}$ groups on the (111) planes created surface defects, which were very reactive and, more likely, easily underwent graphitization.

The results obtained are in a full agreement with the reaction mechanism model suggested earlier [31], in which active surface groups located on prismatic planes of $\mathrm{sp}^{2}$-carbon play a fundamental role in the oxidative dehydrogenation of ethylbenzene to styrene, whereas the basal planes dissociatively activate molecular oxygen [15], [17] and [18]. The catalytic activities obtained over UDD and OLC samples in combination with the characterization results reported evidenced that this model was only suitable for $\mathrm{sp}^{2}$-hybridized carbon, over which the styrene formation was the main reaction pathway. The unique properties of the $\mathrm{sp}^{2}$-hybridized carbon structure allow it to maintain the main reaction pathway in favor of the selective styrene formation.

\section{Conclusion}

UDD and OLC were used as model systems to evidence the reactional behavior of $\mathrm{sp}^{3}$-and $\mathrm{sp}^{2}$ carbons as a function of time on stream, which exhibited different pathways for the ODH of ethylbenzene depending on the bonding nature, favoring predominant styrene and benzene formation, respectively. High benzene yield at the beginning of the reaction was only observed when UDD was used as catalyst, in contrary to what was observed over OLC or activated carbon catalysts. The on stream switch of reaction pathway from benzene to styrene over UDD was observed since $\mathrm{sp}^{2}$-carbons were formed on the UDD surface, with the participation of the newly-formed $\mathrm{sp}^{2}$-carbon during the reaction and a loss of surface acidity. This indicated that the same active sites formed during the reaction as these on OLC and activated carbon. The coverage of $\mathrm{sp}^{3}$ carbon planes by $\mathrm{sp}^{2}$ carbons was not complete, and residual $\mathrm{sp}^{3}$ carbon atoms remained available for producing styrene. Catalytic tests over oxygen-pretreated OLC samples proved that the activity of $\mathrm{sp}^{2}$-hybridized carbon in ODH of ethylbenzene to styrene was influenced by the presence of oxygenated species at the carbon surface. Whereas non-treated OLC and OLC oxygen-treated at the reaction temperature exhibited an activation on stream, a pretreatment temperature higher than that of reaction being necessary to create and stabilize the active oxygenated species, assigned be to basic oxygenated surface groups with dehydrogenating properties. This $+55 \mathrm{~K}$ shift in temperature was attributed to the exothermicity of the ODH reaction during the on stream generation/induction period. 


\section{Acknowledgements}

The authors thank financial support from the German Science Foundation DFG. Dr. Burgina and Dr. Yurij Butenko (BIC, Novosibirsk) are thanked for fruitful co-operation and providing the UDD and OLC samples, respectively.

\section{References}

[1] D. James and W.M. Castor, Ullmann's Encycl Ind Chem 25 (1994), pp. 329-344.

[2] E.H. Lee, Catal Rev 8 (1973), p. 285.

[3] Z.Q. Sun and J. Wang, Appl Catal A 234 (2002), p. 179.

[4] J. Matsui, T. Sodesawa and F. Nozaki, Appl Catal 67 (1997), p. 179.

[5] S.S.E.H. Elnashae, B.K. Abdallah, S.S. Elshishini, S. Alkhowaiter, M.B. Noureldeen and T. Alsoudani, Catal Today 64 (2001), p. 151.

[6] F. Cavani and F. Trifiro, Appl Catal A: Gen 133 (1995), p. 219.

[7] T.G. Alkhazov, Kinet Katal 13 (1972), p. 509.

[8] Y. Iwasawa, H. Nobe and S. Ogasawara, J Catal 36 (1973), p. 444.

[9] P.N. Degannes and D.M. Ruthven, Can J Chem Eng 57 (1979), p. $627 . \mid$

[10] G.C. Grunewald and R.S. Drago, J Mol Catal 58 (1990), p. 227.

[11] Lee CS. US Patent No 4652690, 1987.

[12] M.S. Kane, L.C. Kao, R.K. Mariwala, D.F. Hilscher and H.C. Foley, Ind Eng Chem Res 35 (1996), p. 3319.

[13] M.F.R. Pereira, J.J.M. Orfao and J.L. Figueiredo, Appl Catal A 184 (1999), p. 153.

M.F.R. Pereira, J.J.M. Orfao and J.L. Figueiredo, Appl Catal A 196 (2000), p. 43.

M.F.R. Pereira, J.J.M. Orfao and J.L. Figueiredo, Appl Catal A 218 (2001), p. 307.

[14] A. Guerrero-Ruiz and I. Rodriguez-Ramos, Carbon 32 (1994), p. 23.

[15] G. Mestl, N.I. Maksimova, N. Keller, V.V. Roddatis and R. Schlögl, Angew Chem Int Ed 40 (2001), p. 2066.

[16] M.F.R. Pereira, J.L. Figueiredo, J.J.M. Orfao, P. Serp, P. Kalck and Y. Kihn, Carbon 42 (2004), p. 2807.

[17] N. Keller, N.I. Maksimova, V.V. Roddatis, M. Schur, G. Mestl and Yu.V. Butenko et al., Angew Chem Int Ed 41 (2002), p. 1885.

[18] D.S. Su, N. Maksimova, J.J. Delgado, N. Keller, G. Mestl and M.J. Ledoux et al., Catal Today 102-103 (2005), p. 110.

[19] C. Kuhrs, Y. Arita, W. Weiss, W. Ranke and R. Schlögl, Top Catal 14 (2001), p. 111.

[20] J.A. Macia-Agullo, D.C. Amoros and A.L. Solano, Proceedings of the Reunion de la Sociedad Espanola de Catalisis (2001), p. 97. 
[21] J.A. Macia-Agullo, D. Cazorla-Amoros, A. Linares-Solano, U. Wild, D.S. Su and R. Schlögl, Catal Today 102-103 (2005), p. 248.

[22] V.L. Kuznetsov, A.L. Chuvilin, Yu.V. Butenko, I.Yu. Malkov and V.M. Titov, Chem Phys Lett 222 (1994), p. 343.

[23] V.L. Kuznetsov, A.L. Chuvilin, E.M. Moroz, V.L. Kolomiichuk, Sh.K. Shaikhutdinov and Yu.V. Butenko et al., Carbon 32 (1994), p. 873.

[24] E.D. Obraztsova, S.M. Pimenov, V.I. Konov, M. Fujii, S. Hayashi and V.L. Kuznetsov et al., Mol Mater 10 (1998), p. 249.

[25] P.E. Fanning and M.A. Vannice, Carbon 31 (1993), p. 721.

[26] H.P. Boehm and H. Knözinger In: J.R. Anderson and M. Boudart, Editors, Catalysis vol. 4, Springer Verlag, Berlin, Heidelberg, New York (1983), p. 64.

[27] T. Jiang and K. Xu, Carbon 33 (1995), p. 1663.

[28] H.P. Boehm, Carbon 32 (1994), p. 759.

[29] J.M. O’Reilly and R.A. Mosher, Carbon 21 (1983), p. 47.

[30] T. Evans In: J.E. Field, Editor, Changes produced by high temperature treatment of diamond, The properties of diamond, Academic Press, London, New York, San Francisco (1979), pp. 403-424.

[31] G. Emig and H. Hofmann, J Catal 84 (1983), p. 15. 